\title{
miR-592 acts as an oncogene and promotes medullary thyroid cancer tumorigenesis by targeting cyclin-dependent kinase 8
}

\author{
TING LIU ${ }^{1}$, JINGJING MENG ${ }^{2}$ and YU ZHANG ${ }^{3}$ \\ Departments of ${ }^{1}$ Nuclear Medicine and ${ }^{2}$ Thyroid and Breast Surgery, The Affiliated Wuhan Central Hospital of \\ Tongji Medical College, Huazhong University of Science and Technology, Wuhan, Hubei 430014; \\ ${ }^{3}$ Department of Surgery II, Shanghai Municipal Hospital of Traditional Chinese Medicine, \\ Shanghai University of Traditional Chinese Medicine, Shanghai 200071, P.R. China
}

Received August 19, 2019; Accepted March 25, 2020

DOI: $10.3892 / \mathrm{mmr} .2020 .11392$

\begin{abstract}
Medullary thyroid carcinoma (MTC) is a relatively rare subtype of thyroid cancer, accounting for $5-10 \%$ of all cases of thyroid cancer worldwide. Due to the current lack of knowledge regarding the tumorigenesis of MTC, the clinical treatment of MTC remains a challenge. It has been reported that microRNAs (miRNAs) regulate the progression of MTC; however, the regulatory network of miRNAs and the exact underlying mechanisms are not completely understood. In the present study, an miRNA expression profile (GSE40807), consisting of 80 samples, was downloaded and analyzed using Gene Expression Omnibus-2R to identify differentially expressed miRNAs between MTC and normal samples. miR-592 expression levels were significantly increased in MTC tissues and cell lines compared with normal tissues and cell lines. Patients with high miR-592 expression levels exhibited a less favorable prognosis compared with patients with low miR-592 expression. The results suggested that miR-592 overexpression promoted TT and MZ-CRC-1 cell proliferation in vitro. In addition, miR-592 negatively regulated cyclin-dependent kinase 8 (CDK8) via targeted binding in MTC cells. Moreover, co-transfection of CDK8 overexpression plasmid and miR-592 mimic reversed miR-592-mediated MTC cell proliferation. In conclusion, miR-592 may serve as an oncogene in MTC by decreasing the expression of CDK8, indicating that the miR-592/CDK 8 axis might serve as a promising therapeutic target for MTC.
\end{abstract}

Correspondence to: Dr Yu Zhang, Department of Surgery II, Shanghai Municipal Hospital of Traditional Chinese Medicine, Shanghai University of Traditional Chinese Medicine, 274 Zhijiang Middle Road, Jing'an, Shanghai 200071, P.R. China

E-mail: zy190801@sohu.com

Key words: medullary thyroid carcinoma, microRNA-592, cyclin-dependent kinase 8 , proliferation

\section{Introduction}

Thyroid cancer is the most common subtype of endocrine cancer worldwide, with an increasing incidence level (1). Thyroid cancer can be divided into multiple subtypes, the majority of which originate from follicular cells. Medullary thyroid cancer (MTC), which accounts for 5-10\% of all cases of thyroid cancer, is the only type that originates from parafollicular $\mathrm{C}$ cells $(2,3)$. Patients with MTC with an obvious thyroid nodule frequently present with cervical metastases and $\sim 13 \%$ present with distant metastases $(4,5)$. The 10 -year MTC-specific mortality rate ranges from $13.5-38 \%$ worldwide (6). The clinical stage at the time of diagnosis and the probability of complete surgical removal of the tumor are the two most important determinants for the successful treatment of MTC (7). The prognostic factors of patients with MTC who undergo surgical resection include tumor volume, metastases and location, age, calcitonin level and carcinoembryonic antigen doubling times (8). In the last decade, advancements have been made in the diagnosis and therapeutic treatment of human non-MTC; however, the physiopathology of MTC is not completely understood $(9,10)$. Therefore, exploring molecular targets that may improve the accuracy of MTC diagnosis is important.

MicroRNAs (miRNA) are small single-stranded non-coding RNAs, $\sim 22$ nucleotides in length, that widely exist in mammalian cells $(11,12)$. Due to the limitations of research technologies, miRNAs were initially considered to be noise of transcription without biological functions (13). Progression in next-generation sequencing has made it possible to identify the expression profiles of miRNAs, thereby allowing their functions during the pathogenesis of various human diseases to be investigated (14). At present, the regulatory role of miRNAs on gene expression has been well demonstrated, with increasing evidence indicating that miRNAs can degrade target mRNAs or repress translation (15). miRNA dysregulation is a critical event during the initiation and progression of tumors $(16,17)$, and recently, it has also been reported that miRNAs are implicated during the tumorigenesis of MTC (18); however, the roles of the majority of miRNAs in MTC are not completely understood.

To identify unique miRNAs associated with the tumorigenesis of MTC, differentially expressed miRNAs in the 
GSE40807 dataset were assessed using the Gene Expression Omnibus (GEO)2R method. miR-592 expression was increased in MTC samples compared with normal samples, which indicated that miR-592 may serve a role during the tumorigenesis of MTC. It has been previously reported that miR-592 affects the development of various human tumors, including glioma and acute myeloid leukemia, as well as gastric and breast cancer (19-22); however, the role and mechanism of miR-592 during MTC is not completely understood. Therefore, the present study aimed to investigate the physiological functions and potential mechanisms underlying miR-592 during MTC tumorigenesis.

\section{Materials and methods}

Microarray dataset. The MTC-associated miRNA GEO dataset GSE40807, consisting of 80 samples, was downloaded from the GEO database (www.ncbi.nlm.nih.gov/geo) (23). Differentially expressed miRNAs in GSE40807 were identified using GEO2R.

MTC tumor samples. A total of 20 paired cancer and normal tissue specimens (distance from tumor margin, $5 \mathrm{~cm}$ ) were collected from patients with MTC (mean age, $66.53 \pm 12.48$ years; 8 female patients and 12 male patients) who were diagnosed at the Affiliated Wuhan Central Hospital of Tongji Medical College between March 2015 and October 2019. Tissue samples were stored in liquid nitrogen until further analysis. The present study was approved by the Ethics Committee of The Affiliated Wuhan Central Hospital of Tongji Medical College, Huazhong University of Science and Technology. Written informed consent was obtained from each participant. The basic clinicopathological features of the 20 patients with MTC are presented in Table I. Moreover, the number of patients with different pathological grade, tumor size, $\mathrm{T}$ stage, $\mathrm{N}$ stage, $\mathrm{M}$ stage and TNM stage was determined.

Cell lines. The immortalized normal thyroid follicular NThy-ori-3.1 cell line, and the MTC TT and MZ-CRC-1 cell lines were purchased from the American Type Culture Collection. Cells were cultured in RPMI-1640 (Gibco; Thermo Fisher Scientific, Inc.) containing $10 \%$ fetal bovine serum (Gibco; Thermo Fisher Scientific, Inc.) at $37^{\circ} \mathrm{C}$ and $5 \% \mathrm{CO}_{2}$.

RNA transfection. miR-592 mimic (5'-UGUAGUAGCGUA UAACUGUGUU-3'), scramble mimic (5'-UUCUCCGAACGU GUCACGUTTACGUGACACGUUCGGAGAATT-3') and the CDK8 plasmid were designed and obtained from Shanghai GenePharma Co., Ltd. TT and MZ-CRC-1 cells were seeded $\left(1 \times 10^{5}\right.$ cells/well) into 6 -well plates and cultured at $37^{\circ} \mathrm{C}$ for $8 \mathrm{~h}$. Subsequently, cells were transfected with $200 \mu \mathrm{l} \mathrm{mimic}$ $(100 \mathrm{nM})$ or scramble $(100 \mathrm{nM})$ or $1 \mu \mathrm{g}$ plasmid using Lipofectamine $^{\circledR} 3000$ (Invitrogen; Thermo Fisher Scientific, Inc.), according to the manufacturer's protocol. At $48 \mathrm{~h}$ post-transfection, cells were used for subsequent experiments.

RNA extraction and quantitative real-time PCR $(R T-q P C R)$ assay. Total RNA was extracted from MTC tissue samples and cells using TRIzol ${ }^{\circledR}$ reagent (Invitrogen; Thermo Fisher Scientific, Inc.). RNA quality was determined using a NanoDrop 2000c spectrophotometer (Thermo Fisher Scientific, Inc.). Total RNA (3 $\mu \mathrm{g}$ ) was reverse transcribed into cDNA using the Bestar qPCR RT kit (DBI Bioscience; cat. no. DBI-2220). The temperature protocol used for reverse transcription was $37^{\circ} \mathrm{C}$ for $15 \mathrm{~min}$ and $98^{\circ} \mathrm{C}$ for $5 \mathrm{~min}$. Subsequently, qPCR was performed using the Bestar qPCR MasterMix (DBI Bioscience) and an ABI 7500 system (Applied Biosystems; Thermo Fisher Scientific, Inc.), according to the manufacturer's protocol. The following thermocycling conditions were used for qPCR: $95^{\circ} \mathrm{C}$ for $2 \mathrm{~min} ; 95^{\circ} \mathrm{C}$ for $10 \mathrm{sec}$, $60^{\circ} \mathrm{C}$ for $34 \mathrm{sec}, 72^{\circ} \mathrm{C}$ for $30 \mathrm{sec}$; and the solubility curve was obtained at $98^{\circ} \mathrm{C}$. The primers used for qPCR are presented in Table II. miRNA and mRNA expression levels were quantified using the $2^{-\triangle \Delta C q}$ method (24) normalized to the internal reference genes U6 and GAPDH, respectively.

Data analysis. The data used for the analysis of miR-592 or CDK8 expression and the overall survival of patients with high and low miR-592 or CDK8 expression were downloaded from starBase (version 3; starbase.sysu.edu.cn/panCancer. php). Kaplan-Meier plots (www.kmplot.com) was applied to analyze the association between overall survival and miR-592 or CDK8 expression in patients with MTC. Kalpan-Meier plots were compared using the log-rank test.

Western blotting. Total protein was extracted from transfected TT and MZ-CRC-1 cells using RIPA buffer (cat. no. R0278; Sigma-Aldrich; Merck KGaA). Total protein was quantified using a BCA kit (Pierce; Thermo Fisher Scientific, Inc.). Subsequently, proteins $(30 \mu \mathrm{g})$ were separated via $10 \%$ SDS-PAGE and transferred to nitrocellulose membranes (EMD Millipore). Following blocking with 5\% skim milk at room temperature for $1.5 \mathrm{~h}$, the membranes were incubated at $4^{\circ} \mathrm{C}$ overnight with anti-CDK8 (1:1,000; cat. no. ab224828; Abcam) and anti-GAPDH (1:2,000; cat. no. ab8245; Abcam) primary antibodies. Following washing with PBS, the membranes were incubated with anti-mouse or anti-rabbit horseradish peroxidase-conjugated secondary antibodies (cat. nos. SC-2005 and SC-2004, respectively) at room temperature for $1 \mathrm{~h}$. Protein bands were visualized using ECL Plus reagent (Beyotime Institute of Biotechnology). GAPDH was used as the loading control. Protein expression levels were quantified using Quantity One software (version 4.62; Bio-Rad Laboratories, Inc.).

MTT assay. TT and MZ-CRC-1 cell viability was determined using the MTT assay at 12, 24, 36 and $72 \mathrm{~h}$ post-transfection. Briefly, MTC cells in the exponential growth phase were collected and seeded $\left(3 \times 10^{4}\right.$ cells/well) into 96 -well plates. Following incubation at $37^{\circ} \mathrm{C}$ for $8 \mathrm{~h}, 20 \mu \mathrm{l}$ MTT solution was added to each well and incubated at $37^{\circ} \mathrm{C}$ for $4 \mathrm{~h}$. Subsequently, $200 \mu \mathrm{l}$ DMSO (cat. no. D4540; Sigma-Aldrich; Merck KGaA) was added to each well at room temperature for $15 \mathrm{~min}$. The absorbance of each well was determined at a wavelength of $490 \mathrm{~nm}$ using a microplate reader.

Colony formation assay. For the cell colony formation assay, at $24 \mathrm{~h}$ post-transfection, TT and MZ-CRC-1 cells were seeded $\left(3 \times 10^{3}\right.$ cells/dish) into $35 \mathrm{~mm}$ culture dishes containing RPMI-1640 and cultured for two weeks at $37^{\circ} \mathrm{C}$ with $5 \% \mathrm{CO}_{2}$ 
Table I. Basic clinicopathological features of patients with MTC.

\begin{tabular}{|c|c|}
\hline Parameters & Patients with MTC $(n=20)$ \\
\hline Age, years & $66.53 \pm 12.48$ \\
\hline Sex, male/female & $12 / 8$ \\
\hline \multicolumn{2}{|l|}{ Pathological grade } \\
\hline Well differentiation & $4(20 \%)$ \\
\hline Moderate differentiation & $13(65 \%)$ \\
\hline Poor differentiation & $3(15 \%)$ \\
\hline \multicolumn{2}{|l|}{ Tumor size, $\mathrm{cm}$} \\
\hline$<5$ & $11(55 \%)$ \\
\hline$\geq 5$ & $9(45 \%)$ \\
\hline \multicolumn{2}{|l|}{ T stage, n (\%) } \\
\hline $\mathrm{T} 1$ & $4(20)$ \\
\hline $\mathrm{T} 2$ & $2(10)$ \\
\hline T3 & $5(25)$ \\
\hline $\mathrm{T} 4$ & $9(45)$ \\
\hline \multicolumn{2}{|l|}{$\mathrm{N}$ stage, n (\%) } \\
\hline N0 & $12(60)$ \\
\hline N1a & $3(15)$ \\
\hline $\mathrm{N} 1 \mathrm{~b}$ & $2(10)$ \\
\hline N1c & $1(5)$ \\
\hline $\mathrm{N} 2 \mathrm{a}$ & $1(5)$ \\
\hline $\mathrm{N} 2 \mathrm{~b}$ & $1(5)$ \\
\hline \multicolumn{2}{|l|}{ M stage, n (\%) } \\
\hline M0 & $19(95)$ \\
\hline M1a & $1(5)$ \\
\hline \multicolumn{2}{|l|}{ TNM stage, n (\%) } \\
\hline II & $3(15)$ \\
\hline IIA & $8(40)$ \\
\hline IIIB & $5(25)$ \\
\hline IIIC & $3(15)$ \\
\hline IVA & $1(5)$ \\
\hline
\end{tabular}

MTC, medullary thyroid cancer.

and $95 \% \mathrm{O}_{2}$. The visible colonies were fixed in $4 \%$ paraformaldehyde at room temperature for $10 \mathrm{~min}$ and stained with 10\% Giemsa solution (cat. no. G4507; Sigma-Aldrich; Merck KGaA) at room temperature for $10 \mathrm{~min}$. Subsequently, the number of colonies was manually counted using a light microscope (magnification, $\mathrm{x} 10$ ).

Cell cycle analysis. TT and MZ-CRC-1 cells in the exponential growth phase were collected and fixed using ethanol $(75 \%)$ overnight at $4^{\circ} \mathrm{C}$. Cells were washed with pre-cooled PBS to remove the excessive ethanol and stained with $200 \mu \mathrm{l} \mathrm{PI}$ at $37^{\circ} \mathrm{C}$ for $30 \mathrm{~min}$. Subsequently, cells were stained with $100 \mu \mathrm{l}$ RNaseA staining buffer (BD Pharmingen) at room temperature for $20 \mathrm{~min}$. Cell cycle was detected by flow cytometry using a FACSCalibur flow cytometer (BD Biosciences). The number of cells in $\mathrm{G}_{0} / \mathrm{G}_{1}, \mathrm{~S}$ and $\mathrm{G}_{2} / \mathrm{M}$ phases was calculated using ModFit software (version 4.1; Verity Software House, Inc.).
Table II. Sequences of primers used for reverse transcriptionquantitative PCR.

\begin{tabular}{|c|c|}
\hline Gene & Sequence $\left(5^{\prime}-3^{\prime}\right)$ \\
\hline GAPDH & $\begin{array}{l}\text { F: TGTTCGTCATGGGTGTGAAC } \\
\text { R: ATGGCATGGACTGTGGTCAT }\end{array}$ \\
\hline miR-592 & $\begin{array}{l}\text { F: CCATGACATTGTGTCAATATGCGA } \\
\text { R: CGTCATGATGTTGCGTCACC }\end{array}$ \\
\hline SCGB2A2 & $\begin{array}{l}\text { F: GAACACCGACAGCAGCA } \\
\text { R: TCTCCAATAAGGGGCAGCC }\end{array}$ \\
\hline U6 & $\begin{array}{l}\text { F: CTCGCTTCGGCAGCACA } \\
\text { R: AACGCTTCACGAATTTGCGT }\end{array}$ \\
\hline LINC00632 & $\begin{array}{l}\text { F: CACGCCTGTTATCCC } \\
\text { R: CAACCTCCGCCTCTT }\end{array}$ \\
\hline CREB3L3 & $\begin{array}{l}\text { F: CAGTCAGCTCAAGAAAGCAGG } \\
\text { R: TGGTTCTGGGCAGTACACG }\end{array}$ \\
\hline OR4F4 & $\begin{array}{l}\text { F: ATAGCCATGGGCTTTGACAG } \\
\text { R: TGGGACCACAGAAGGGTAAG }\end{array}$ \\
\hline CCDC149 & $\begin{array}{l}\text { F: CTCTCCAAGGAGCTGGACAC } \\
\text { R: TCCAAGCCTTTGCTGAAGTT }\end{array}$ \\
\hline CDK8 & $\begin{array}{l}\text { F: GCCGGTTGTCAAATCCCTTAC } \\
\text { R: TGTGACTGCTGTCTTGATTCCCT }\end{array}$ \\
\hline
\end{tabular}

miR, microRNA; F, forward; R, reverse; SCGB2A2, secretoglobin family 2A member 2; LINC00632, long intergenic non-protein coding RNA632; CREB3L3, cAMP responsive element binding protein 3 like 3; OR4F4, olfactory receptor family 4 subfamily F member 4; CCDC149, coiled-coil domain containing 149; CDK8, cyclin-dependent kinase 8.

Functional analysis. The functional roles of miR-592 target genes were analyzed using the Database for Annotation, Visualization and the Integrated Discovery (DAVID; version 6.8; david.ncifcrf.gov/home.jsp). In addition, integration of the Gene Ontology (GO) $(24,25)$ and Kyoto Encyclopedia of Genes and Genomes (KEGG) (26-28) databases was performed.

Dual-luciferase reporter assay. The target genes of miR-592 were identified by TargetScan (version 7.1; www.targetscan. org/vert_71) and the interaction between miR-592 and CDK8 was verified using StarBase (version 2.0; starbase.sysu.edu.cn). The interaction between miR-592 and CDK8 in MTC cells was examined using a dual-luciferase reporter assay. The wild-type (WT) and mutant (Mut) CDK8 3'-untranslated region (UTR) containing miR-592 complementary sequences were cloned into the pGL3 vector (Promega Corporation) to form CDK8-WT and CDK8-Mut luciferase plasmids, respectively. TT and MZ-CRC-1 cells ( $1 \times 10^{5}$ cells/well) were plated in a 6-well plate and cultured for $8 \mathrm{~h}$. Subsequently, cells were co-transfected with $100 \mathrm{ng}$ CDK8-WT or $100 \mathrm{ng}$ CDK8-Mut and $20 \mathrm{nM}$ miR-592 mimic or $20 \mathrm{nM}$ scramble mimic using Lipofectamine $^{\circledR} 3000$ (Invitrogen; Thermo Fisher Scientific, Inc.) according to the manufacturer's protocol. Following incubation at $37^{\circ} \mathrm{C}$ for $48 \mathrm{~h}$, luciferase activities were detected using the Dual-Luciferase Assay System (Promega Corporation), 
A

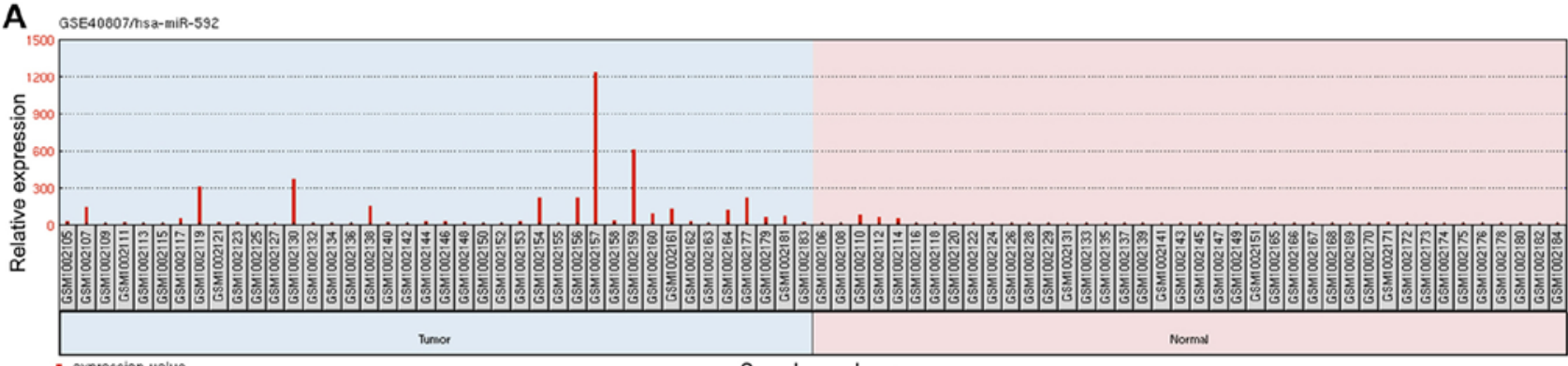

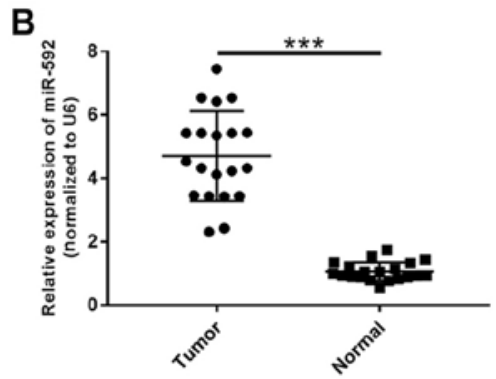

E

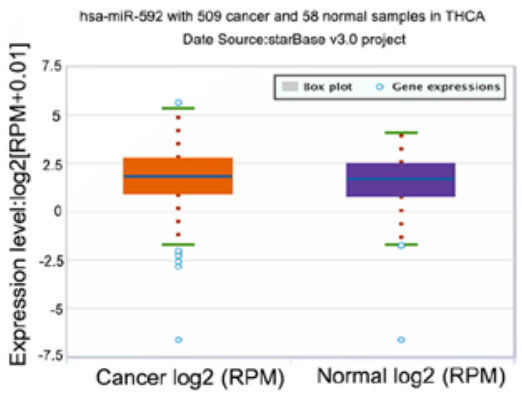

C

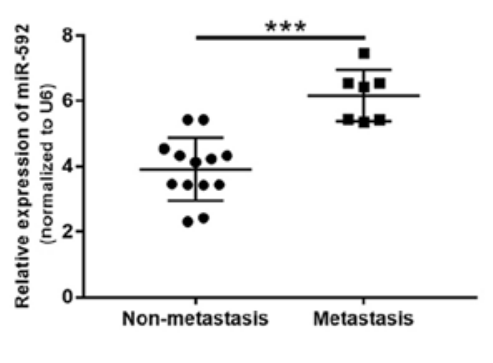

$\mathbf{F}$

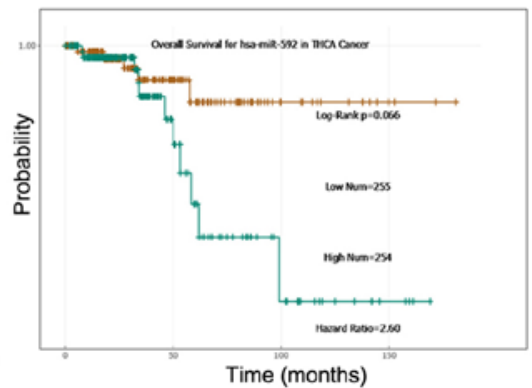

D

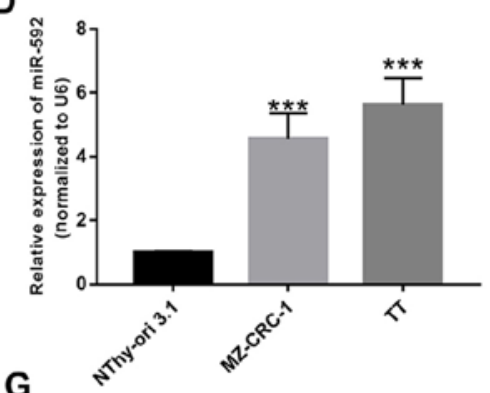

G

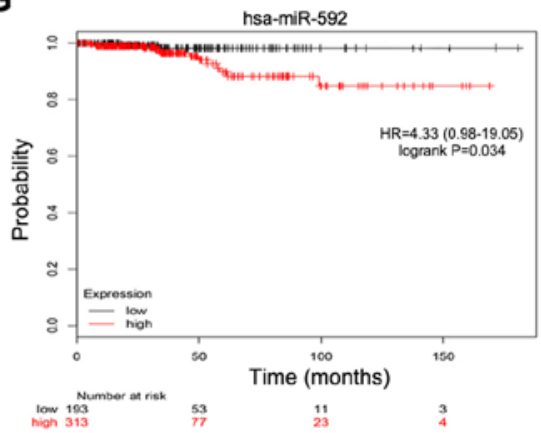

Figure 1. miR-592 expression is increased during MTC. (A) GEO2R analysis was performed to identify differentially expressed miRNAs between MTC and normal samples obtained from the GSE40807 dataset. miR-592 expression levels in (B) 20 paired MTC and normal samples, as well as (C) non-metastatic and metastatic tumor samples. ${ }^{* * *} \mathrm{P}<0.001$. (D) miR-592 expression levels in the MTC MZ-CRC-1 and TT cell lines, and the normal thyroid follicular NThy-ori-3.1 cell line. ${ }^{* * *} \mathrm{P}<0.001$. (E) The mean expression of miR-592 in 509 MTC and 58 normal samples obtained from the starBase database. (F) Overall survival rate of patients with MTC with high or low miR-592 expression. (G) Kaplan-Meier survival curves of patients with MTC with high or low miR-592 expression in the Kaplan-Meier Plotter database. ${ }^{* * *} \mathrm{P}<0.001$, as indicated. MTC, medullary thyroid cancer; miR/miRNA, microRNA; THCA, thyroid carcinoma; HR, hazard ratio.

according to the manufacturer's protocol. Firefly luciferase activity was normalized to Renilla luciferase activity.

Gene regulatory network. Based on previous studies (29-31), the gene regulatory network of CDK8 was analyzed and identified using GENEVESTIGATOR ${ }^{\circledR}$ (genevestigator.com/gv).

Statistical analysis. Data are presented as the mean \pm SD. Statistical analyses were performed using GraphPad Prism software (version 7; GraphPad Software, Inc.). Differences between two groups were analyzed using the paired (comparisons between paired and normal tissue samples) or unpaired (other data) Student's t-test. Differences among multiple groups were analyzed using one-way ANOVA with Tukey's post hoc test. $\mathrm{P}<0.05$ was considered to indicate a statistically significant difference.

\section{Results}

miR-592 expression is increased during MTC. To identify miRNAs that may contribute to the tumorigenesis of MTC, differentially expressed miRNAs in the GSE40807 dataset were analyzed using GEO2R. The relative expression of miR-592 was significantly increased in MTC samples compared with normal samples $(\mathrm{P}<0.05$; Fig. 1A). To further investigate the expression of miR-592 during MTC, miR-592 expression levels were examined in 20 paired MTC and corresponding normal samples using RT-qPCR. miR-592 expression levels were significantly increased in MTC samples compared with normal samples $(\mathrm{P}<0.001$; Fig. 1B). Moreover, miR-592 expression levels were significantly increased in metastatic MTC samples compared with non-metastatic samples ( $\mathrm{P}<0.001$; Fig. 1C). In addition, the expression levels of miR-592 in MTC cell lines were assessed. The results indicated that miR-592 expression was also significantly increased in TT and MZ-CRC-1 cells compared with NThy-ori 3.1 cells ( $\mathrm{P}<0.001$; Fig. 1D). Furthermore, the starBase analysis suggested that miR-592 expression levels were increased in MTC samples compared with normal samples (Fig. 1E). The starBase analysis results also indicated that overall survival was not significantly different between patients with MTC with high and low miR-592 expression (Fig. 1F). However, the Kaplan-Meier survival curves demonstrated that patients with high miR-592 expression exhibited a significantly less favorable prognosis compared with patients with low miR-592 expression ( $\mathrm{P}=0.034$; 
A

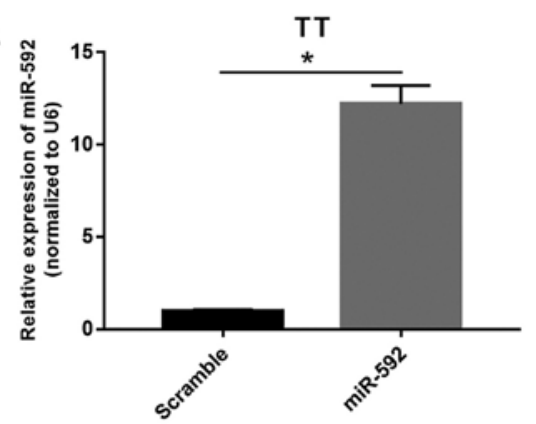

C

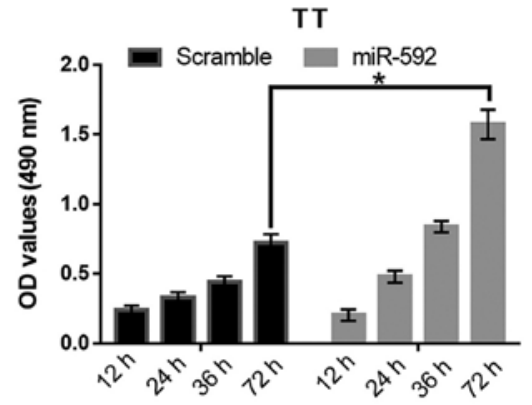

E

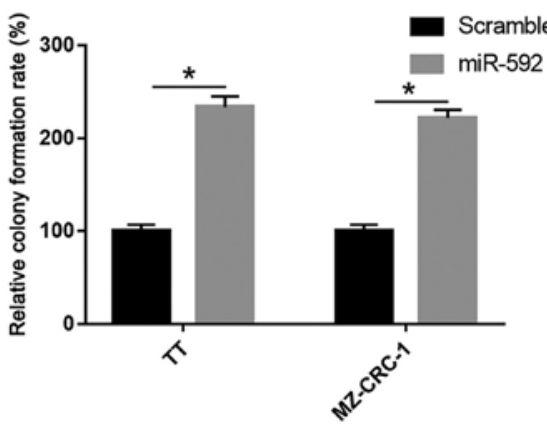

G

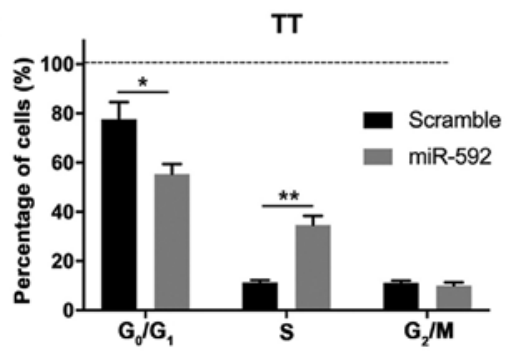

B

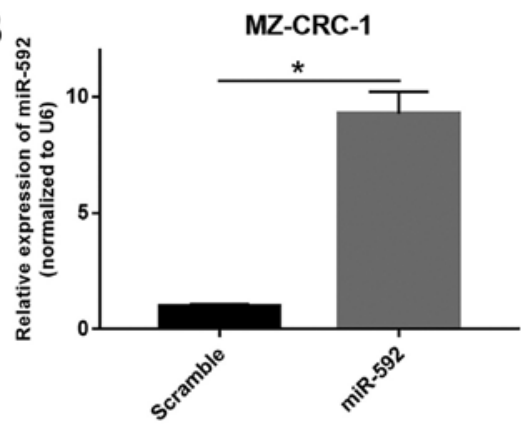

D

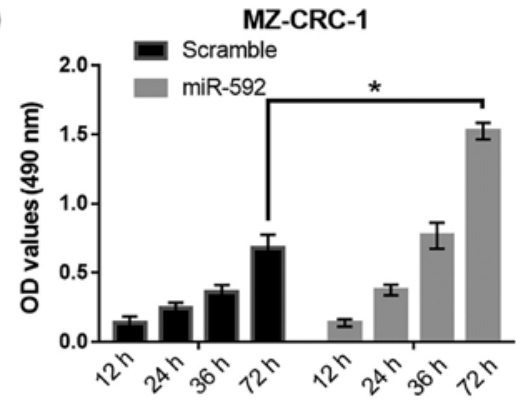

$\mathbf{F}$
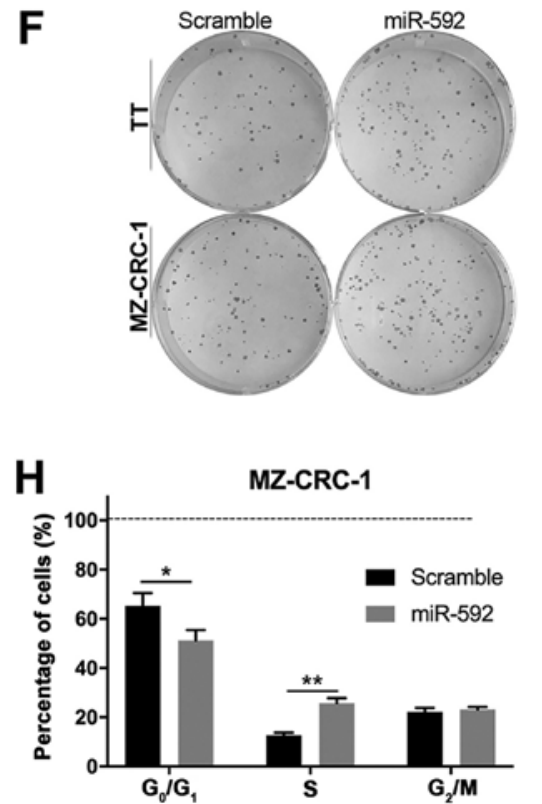

Figure 2. miR-592 overexpression increases MTC cell proliferation. miR-592 expression levels in (A) TT and (B) MZ-CRC-1 cells transfected with miR-592 mimic or scramble mimic. The MTT assay was performed to assess (C) TT and (D) MZ-CRC-1 cell viability at 12, 24, 36 and $72 \mathrm{~h}$ post-transfection with miR-592 mimic or scramble mimic. (E) The colony formation assay was performed to investigate the effect of miR592 overexpression on TT and MZ-CRC-1 cell proliferation. (F) Representative images of the colony formation assay. Flow cytometry was performed to analyze the cell cycle distribution of $(\mathrm{G}) \mathrm{TT}$ and (H) MZ-CRC-1 cells transfected with miR-592 mimic and scramble mimic. " $\mathrm{P}<0.05$ and ${ }^{* * *} \mathrm{P}<0.01$. miR, microRNA; MTC, medullary thyroid cancer.

Fig. 1G). Collectively, the results indicated that miR-592 may serve a role during MTC tumorigenesis.

miR-592 overexpression facilitates MTC cell proliferation. To investigate the precise functions of miR-592 during MTC tumor development, TT and MZ-CRC-1 cells were transfected with miR-592 mimic. Subsequently, cell proliferation, viability and cell cycle distribution were assessed using MTT, colony formation and flow cytometry assays. The miR-592 mimic group exhibited significantly increased miR-592 expression levels compared with the scramble mimic group in both TT and MZ-CRC-2 cells, which indicated that miR-592 mimic transfection was successful $(\mathrm{P}<0.05$; Fig. 2A and B). miR-592 overexpression significantly increased TT and MZ-CRC-1 cell viability compared with the scramble group $(\mathrm{P}<0.05$; Fig. $2 \mathrm{C}$ and $\mathrm{D})$. miR-592 overexpression also significantly increased the colony formation rate compared with the scramble group in both TT and MZ-CRC-1 cells ( $\mathrm{P}<0.05$; Fig. 2E and F). Moreover, miR-592 overexpression significantly decreased the number of cells in the $G_{0} / G_{1}$ phase and significantly increased the number of cells in the $S$ phase compared with the scramble group in both TT and MZ-CRC-1 cells $(\mathrm{P}<0.05$; Fig. $2 \mathrm{G}$ and $\mathrm{H})$. The results suggested that miR-592 overexpression promoted MTC cell proliferation.

Significantly enriched GO terms and KEGG pathways of $m i R-592$. The target genes of miR-592 were identified by 
A
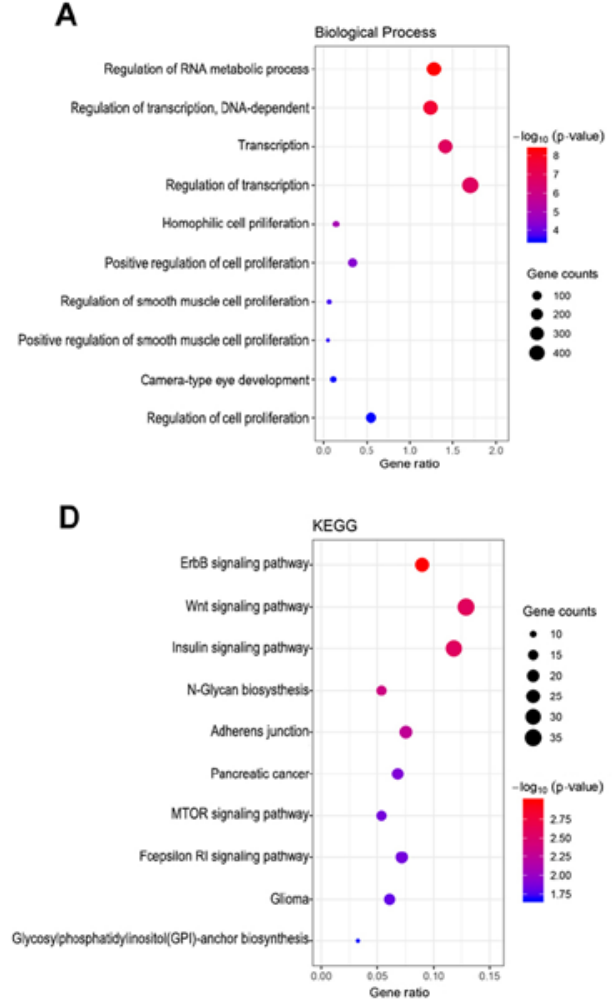

B

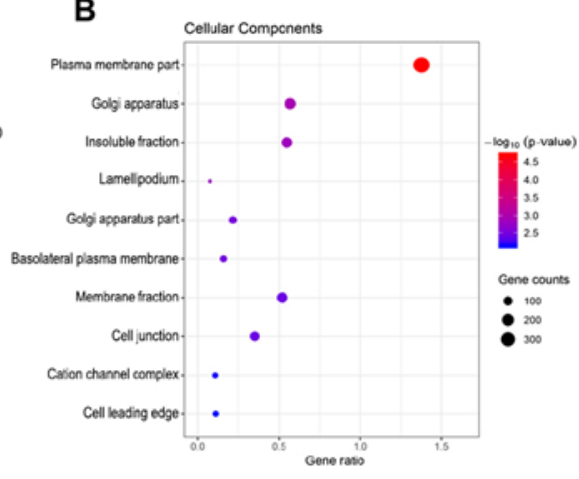

E

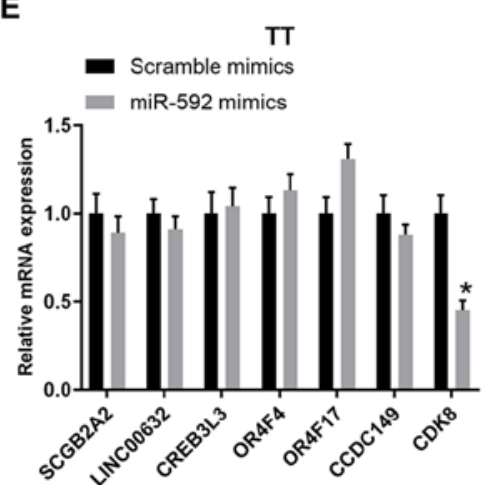

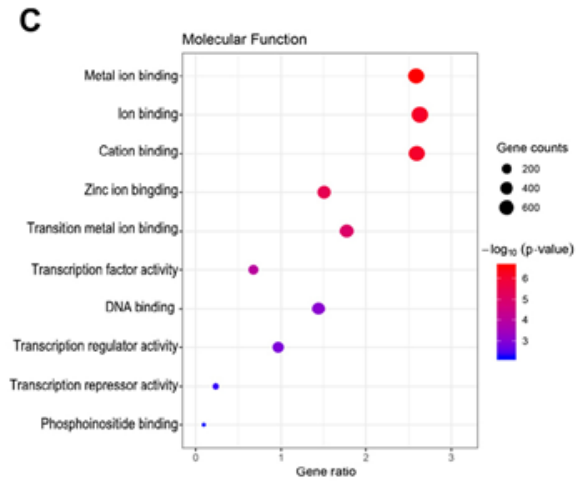

$\mathbf{F}$

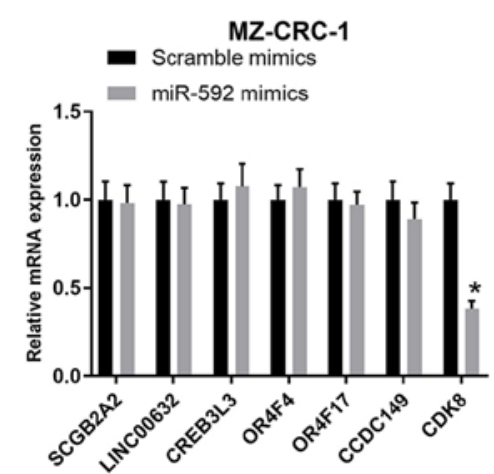

Figure 3. Significantly enriched GO terms and KEGG pathways of miR-592. (A) Biological process, (B) cellular component and (C) molecular function GO terms. (D) KEGG pathways. The relative expression levels of multiple miR-592 target genes in (E) TT and (F) MZ-CRC-1 cells transfected with miR-592 mimic or scramble mimic. "P<0.05 vs. the scramble mimic group. GO, Gene Ontology; KEGG, Kyoto Encyclopedia of Genes and Genomes; miR, microRNA.

TargetScan and categorized into biological process (BP), cellular component (CC) and molecular function (MF) GO categories via DAVID analysis (Fig. 3A-C). Moreover, the target genes were functionally assessed by KEGG analysis, which indicated that the target genes were associated with several pathways, including the 'Wnt signaling pathway', 'ErbB signaling pathway', 'insulin signaling pathway', 'N-Glycan biosynthesis' and 'Adherens junction' (Fig. 3D). Moreover, the mRNA expression levels of multiple miR-592 target genes in miR-592 mimic-transfected TT and MZ-CRC-1 cells were assessed by RT-qPCR. miR-592 overexpression significantly decreased CDK8 expression levels compared with the scramble mimic group in both TT and MZ-CRC-1 cells $(\mathrm{P}<0.05$; Fig. $3 \mathrm{E}$ and $\mathrm{F})$; therefore, $\mathrm{CDK} 8$ was selected for further analysis.

miR-592 binds to and negatively regulates CDK8 in MTC cells. To determine whether CDK8 was regulated by miR-592 in MTC cells, the mRNA expression levels of CDK8 in miR-592 mimic-transfected TT and MZ-CRC-1 cells were measured by RT-qPCR. Compared with the scramble mimic group, the expression levels of CDK8 were significantly decreased in miR-592 mimic-transfected TT and MZ-CRC-1 cells (Fig. 4A). Moreover, it was predicted that CDK8 3'-UTR possessed an miR-592 binding site (Fig. 4B). Subsequently, a dual-luciferase reporter assay was performed in TT and MZ-CRC-1 cells to verify the interaction between miR-592 and CDK8. The luciferase activities of TT and MZ-CRC-1 cells co-transfected with miR-592 mimic and CDK8-WT were significantly decreased compared with TT and MZ-CRC-1 cells co-transfected with scramble mimic and CDK8-WT. The luciferase activities of TT and MZ-CRC-1 cells co-transfected with miR-592 mimic and CDK8-Mut were not significantly different compared with TT and MZ-CRC-1 cells co-transfected with scramble mimic and CDK8-Mut $(\mathrm{P}<0.05$; Fig. $4 \mathrm{C}$ and $\mathrm{D})$. In addition, CDK8 expression levels in 510 MTC samples and 58 normal samples obtained from the starBase database were assessed. CDK8 expression was downregulated in MTC samples compared with normal samples (Fig. 4E). There was no significant difference in the survival rate of patients with MTC with high and low CDK8 expression (Fig. 4F and G). Furthermore, a negative correlation between the expression levels of miR-592 and CDK8 in MTC was identified using starBase (Fig. 4H).

CDK8 overexpression reverses miR-592-mediated MTC cell proliferation. Subsequently, whether CDK8 was associated with miR-592-mediated MTC cell proliferation was investigated by co-transfecting TT and MZ-CRC-1 cells with miR-592 mimic and a CDK8 overexpression plasmid. Co-transfection of TT and MZ-CRC-1 cells with miR-592 mimic and the CDK8 overexpression plasmid reversed miR-592 mimic-mediated downregulation of $\mathrm{CDK} 8$ expression $(\mathrm{P}<0.05$; Fig. 5A-D). The results of the colony formation assay indicated that miR-592 mimic and CDK8 overexpression plasmid co-transfection significantly decreased miR-592 mimic-induced colony formation of TT and MZ-CRC-1 cells $(\mathrm{P}<0.05$; Fig. $5 \mathrm{E}$ and $\mathrm{F})$. miR-592 overexpression decreased the number of cells in the $\mathrm{G}_{0} / \mathrm{G}_{1}$ phase and increased the number of cells in the $S$ phase in both TT and MZ-CRC-1 cells; however, co-transfection of miR-592 mimic and CDK8 overexpression plasmid reversed 
A
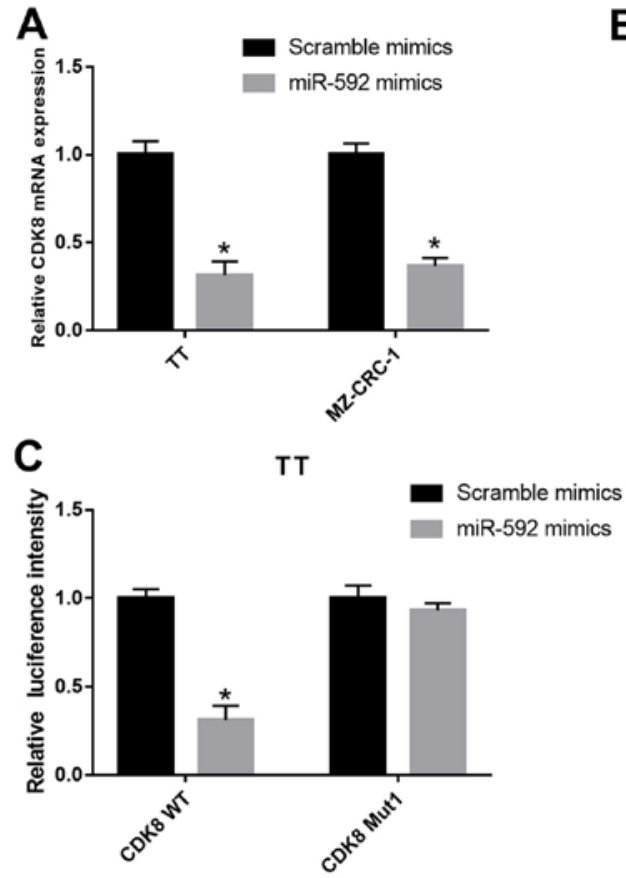

E

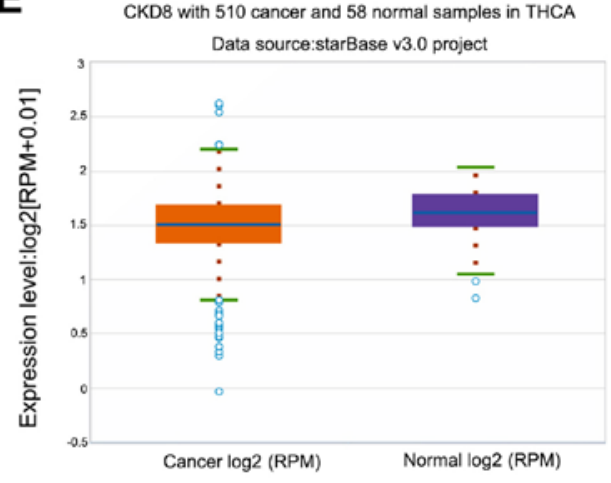

G

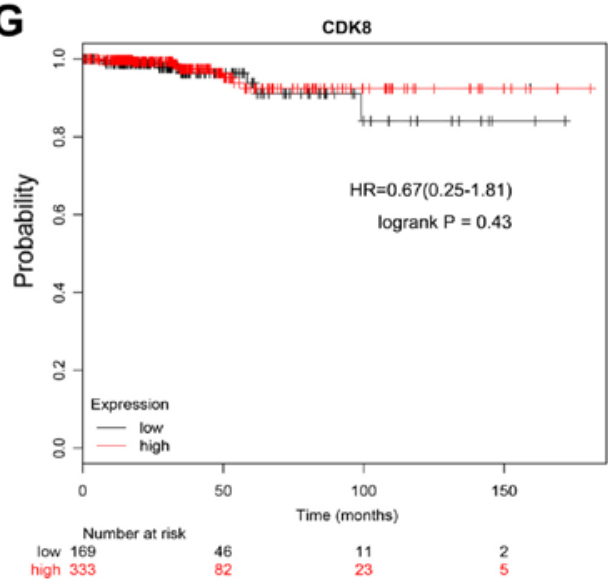

B

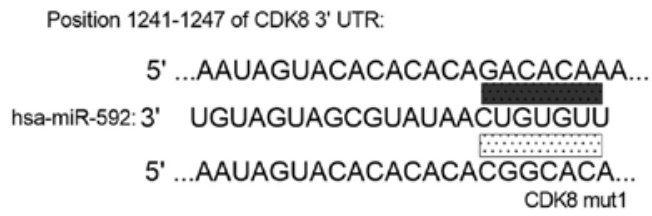

Position 1915-1922 of CDK8 3' UTR:

$55^{\prime}$...ACUAUUUUACAUGAAUGACACAA...

hsa-miR-592:3' UGUAGUAGCGUAUAACUGUGUU

5' ...ACUAUUUUACAUGAAACGGCGCC..

D CDK8 mut2

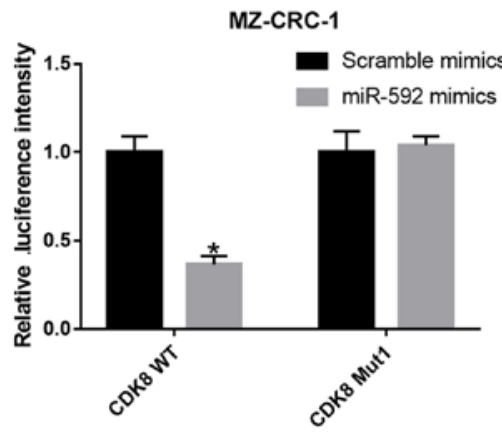

$\mathbf{F}$

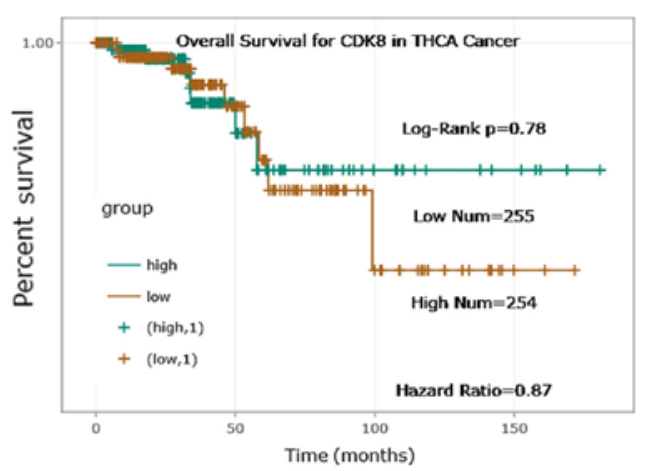

H

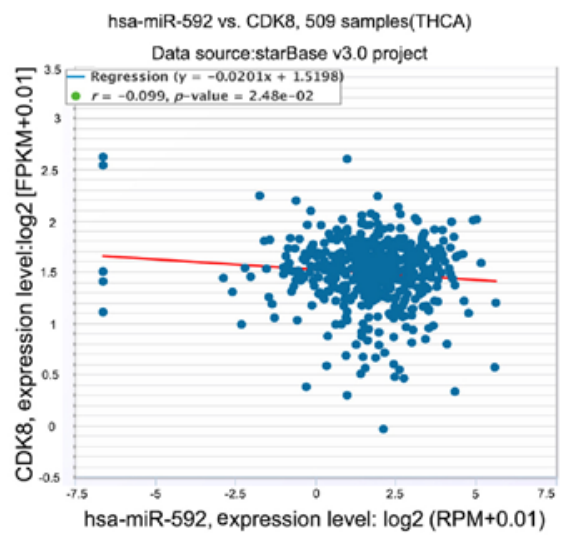

Figure 4. miR-592 binds to and negatively regulates CDK8 in MTC cells. (A) CDK8 expression levels in TT and MZ-CRC-1 cells transfected with miR-592 mimic and scramble mimic. (B) The predicted binding site between CDK8 and miR-592. The interaction between CDK8 and miR-592 was further investigated in (C) TT and (D) MZ-CRC-1 cells transfected with miR-592 mimic and scramble mimic using a dual-luciferase reporter assay. (E) CDK8 expression levels in 510 MTC and 58 normal samples obtained from the starBase database. (F) Overall survival rate of patients with MTC with high or low CDK8 expression. (G) Kaplan-Meier survival curves of patients with MTC with high and low CDK8 expression in the Kaplan-Meier Plotter database. (H) Correlation between CDK8 and miR-592 expression in MTC samples. "P<0.05 vs. scramble mimic. miR, microRNA; CDK8, cyclin-dependent kinase 8; MTC, medullary thyroid cancer; 3'UTR, 3'-untranslated regions; WT, wild-type; Mut, mutant; THCA, thyroid carcinoma; FPKM, fragments per kilobase of transcript per million mapped reads; HR, hazard ratio.

miR-592 overexpression-induced effects on cell cycle distribution $(\mathrm{P}<0.05$; Fig. 5G and $\mathrm{H})$. The results indicated that $\mathrm{CDK} 8$ overexpression reversed the miR-592-mediated effects on MTC cell proliferation. 

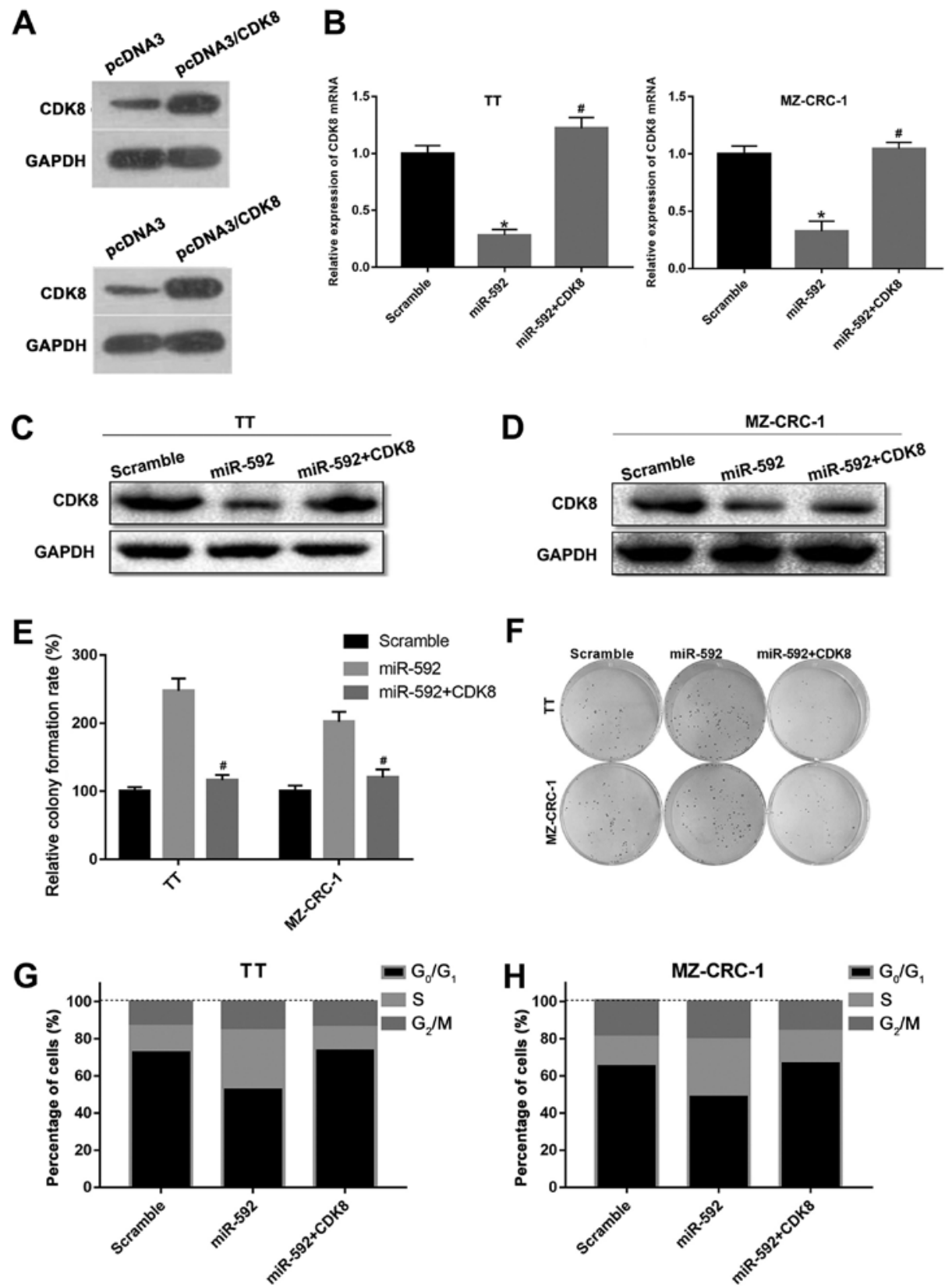

Figure 5. CDK8 overexpression reversed miR-592-mediated MTC cell proliferation. (A) CDK8 expression was confirmed by western blotting in TT and MZ-CRC-1 cells following CDK8 overexpression. (B) CDK8 mRNA expression levels were analyzed by reverse transcription-quantitative PCR in TT and MZ-CRC-1 cells following transfection with miR-592 mimic and/or CDK8-overexpressed plasmid. CDK8 protein expression levels were measured via western blotting in (C) TT and (D) MZ-CRC-1 cells. (E) The colony formation assay was performed to assess TT and MZ-CRC-1 cell proliferation. (F) Representative images of the colony formation assay. Flow cytometry was performed to assess the cell cycle distribution of (G) TT and (H) MZ-CRC-1 cells. " $\mathrm{P}<0.05$ vs. the scramble group; ${ }^{*} \mathrm{P}<0.05$ vs. the miR-592 group. CDK8, cyclin-dependent kinase 8; miR, microRNA; MTC, medullary thyroid cancer.

CDK8 interaction network and the mechanism of miR-592/CDK8 axis in MTC. To understand the regulatory network underlying CDK8 during MTC, CDK8-associated genes were identified using GENEVESTIGATOR and the top $30 \mathrm{CDK}-8$-associated genes are presented in Fig. 6A. Collectively, the results suggested that miR-592 overexpression promoted MTC tumorigenesis by downregulating CDK8 expression (Fig. 6B).

\section{Discussion}

During the past few decades, the expression profiles of miRNAs in different subtypes of thyroid cancer have been analyzed (32). A large number of mammalian miRNAs are upregulated in thyroid tumors, such as miR-650 (33), miR-340-5p (34), miR-424-5p (35) and miR-155 (36); while a number of miRNAs have been reported to be downregulated, such as miR-26a (37), miR-215 (38), miR-34a (39) and miR-206 (40). In addition, a previous study indicated that the expression levels of numerous miRNAs exhibit significant differences in MTC (41).

At present, MTC accounts for $<10 \%$ of all cases of thyroid cancer worldwide, and only a small number of studies have been conducted to examine the expression profiles and biological functions of miRNAs during MTC tumorigenesis (42). The first MTC-associated microarray analysis of 


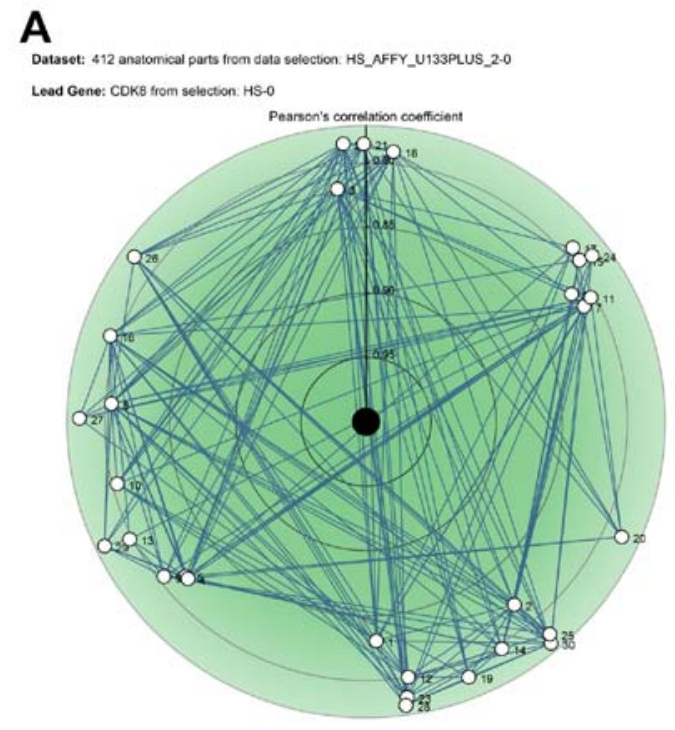

\section{CDK8 interation network by} GENEVESTIGATOR

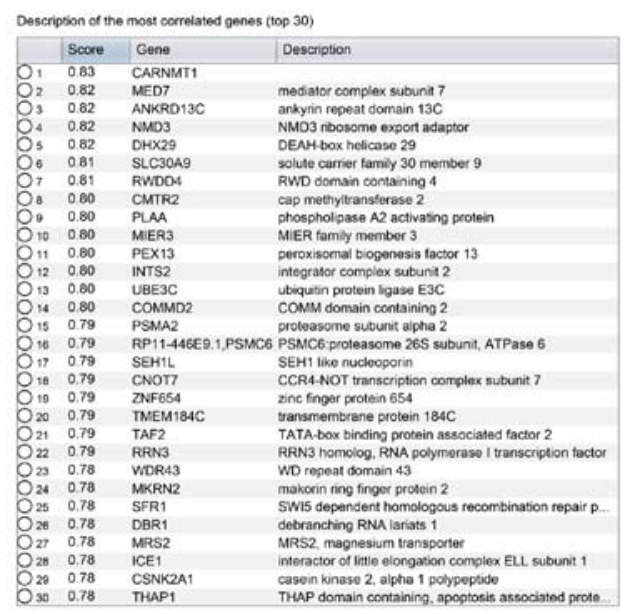

B

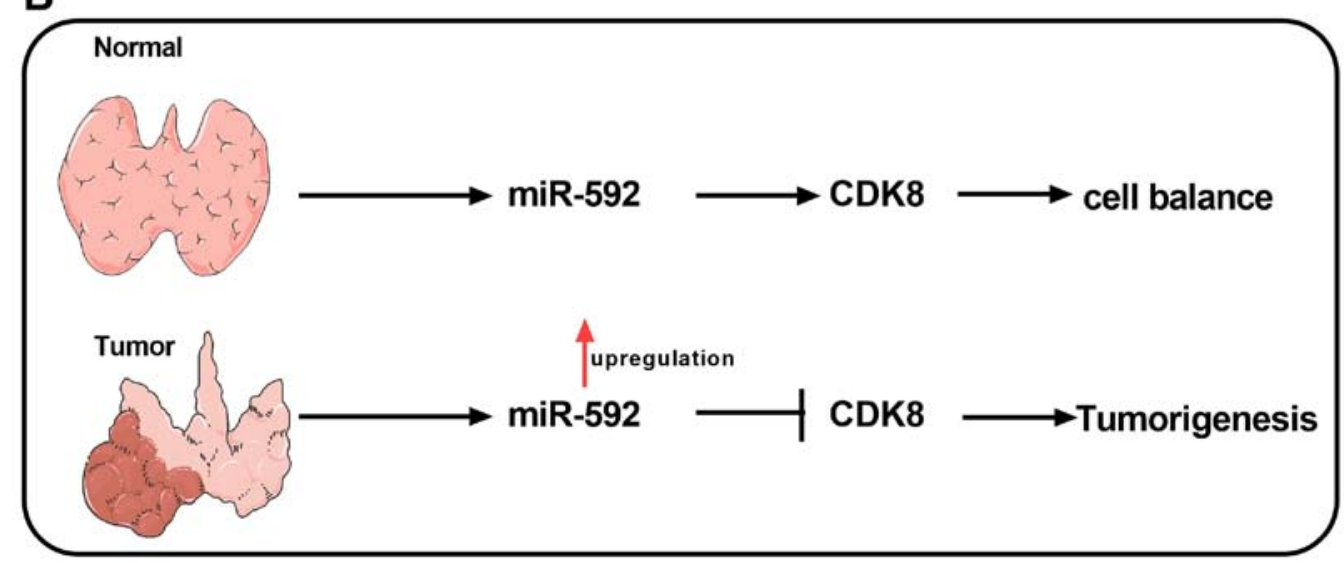

Figure 6. CDK8 interaction network and the mechanism underlying the miR-592/CDK8 axis during MTC.(A) The top 30 CDK-8-associated genes were predicted using GENEVESTIGATOR. (B) The molecular mechanisms underlying the miR-592/CDK8 axis during MTC tumorigenesis. CDK8, cyclin-dependent kinase 8; MTC, medullary thyroid cancer; miR, microRNA.

miRNA expression was conducted by Nikiforova et al (26) in 2008 using two MTC specimens. Hereditary MTC (hMTC) and sporadic MTC (sMTC) are the two subtypes of MTC that account for 25 and $75 \%$ of MTC cases, respectively. A subsequent study demonstrated that the expression levels of miR-183 and miR-375 were increased, while miR-9 expression levels were decreased in sMTC samples compared with hMTC samples using a miRNA microarray analysis in 19 patients with MTC, including 7 hMTC and 12 sMTC cases (43). Moreover, it was also demonstrated that miR-183 and miR-375 upregulation were closely associated with lateral lymph node metastases, representing two promising biomarkers for MTC prognosis (43). Recently, a large miRNA microarray profiling study was conducted to identify differentially expressed miRNAs in MTC, and the results also validated that miR-375 and miR-10a were upregulated, while miR-455 was downregulated in MTC samples compared with normal samples (44). To further investigate the regulatory network and functions of miRNAs during MTC, an miRNA microarray was performed in the present study to analyze differentially expressed miRNAs between MTC and normal samples in the GSE40807 dataset, which was downloaded from the GEO database. Among the differentially expressed miRNAs, miR-592 exhibited a high fold-change; therefore, it was selected for subsequent functional analysis. In the last few years, miR-592 has been reported to be involved in the development of several different types of human cancer $(20,45)$. For example, high expression of miR-592 was demonstrated to be associated with colorectal cancer tumorigenesis and poor prognosis $(46,47)$, miR-592 exhibits an oncogenic effect on prostate cancer cells by repressing Forkhead box O3A (48) and miR-592 facilitates the proliferation, migration and invasion of gastric cancer (49). Therefore, it was speculated that miR-592 may serve as a carcinogenic marker for different types of cancer. Nevertheless, the role of miR-592 in MTC has not been previously reported. In the present study, the RT-qPCR results indicated that miR-592 expression was upregulated in MTC tissue samples and cell lines compared with normal tissue samples and cell lines, and miR-592 overexpression promoted TT and MZ-CRC-1 cell proliferation. To the best of our knowledge, the present study was the first study to suggest that miR-592 may serve an oncogenic role during MTC. 
To further explore the mechanism underlying miR-592 in MTC, the target genes of miR-592 were predicted by bioinformatics followed by functional analysis. CDK8 was identified as a target gene of miR-592, which was negatively regulated by miR-592. Numerous studies have demonstrated that CDK8 serves as a critical oncogenic molecule in various types of human cancer, including colorectal, breast and prostate cancer (50-52). Although the majority of studies support the oncogenic role of CDK8, a number of studies have indicated that CDK8 exerts repressive functions in different types of cancer, including colon $(53)$, breast $(54,55)$, pancreatic (56) and non-small cell lung (57) cancer. The context-specific roles of CDK8 in distinct types of human cancer have received increasing interest and there is considerable controversy regarding the development of CDK8-based therapeutics. In the present study, CDK8 overexpression abolished miR-592-mediated effects on MTC cell proliferation, which implied that CDK8 may serve as a tumor suppressor during MTC.

The present study indicated that miR-592 may serve as an oncogene during MTC by decreasing CDK8 expression, providing a novel therapeutic target for MTC treatment. However, the present study had a number of limitations. The effects of miR-592 inhibitors on the functions of MTC, including cell apoptosis, autophagy, migration, invasion and tumor growth in vivo require further investigation. Additionally, the detailed mechanisms underlying the miR-592/CDK8 axis also require further investigation.

\section{Acknowledgements}

Not applicable.

\section{Funding}

No funding was received.

\section{Availability of data and materials}

The datasets used and/or analyzed during the current study are available from the corresponding author on reasonable request.

\section{Authors' contributions}

TL, JM and YZ designed the study, performed the bioinformatics analysis and the experiments. TL and $Y Z$ performed the statistical analysis. YZ wrote the manuscript. TL and JM revised the manuscript. All authors read and approved the final manuscript.

\section{Ethics approval and consent to participate}

The present study was approved by the Ethics Committee of The Affiliated Wuhan Central Hospital of Tongji Medical College, Huazhong University of Science and Technology. Written informed consent was obtained from each participant.

\section{Patient consent for publication}

Not applicable.

\section{Competing interests}

The authors declare that they have no competing interests.

\section{References}

1. Cabanillas ME, McFadden DG and Durante C: Thyroid cancer. Lancet 388: 2783-2795, 2016.

2. Kushchayev SV, Kushchayeva YS, Tella SH, Glushko T, Pacak K and Teytelboym OM: Medullary thyroid carcinoma: An update on imaging. J Thyroid Res 2019: 1893047, 2019.

3. Hao WJ, Zhang H, Yu Y, Zhao J, Ge ZJ, Ding PX, Sun XX, Liu H, Wen SY and You J: Clinical significance and cost-benefit analysis of serum calcitonin assay in diagnosis and treatment of medullary thyroid carcinoma. Zhonghua Er Bi Yan Hou Tou Jing Wai Ke Za Zhi 54: 506-509, 2019 (In Chinese).

4. Kebebew E, Greenspan FS, Clark OH, Woeber KA and Grunwell J: Extent of disease and practice patterns for medullary thyroid cancer. J Am Coll Surg 200: 890-896, 2005.

5. Roman S, Lin R and Sosa JA: Prognosis of medullary thyroid carcinoma: Demographic, clinical, and pathologic predictors of survival in 1252 cases. Cancer 107: 2134-2142, 2006.

6. Kuo EJ, Sho S, Li N, Zanocco KA, Yeh MW and Livhits MJ: Risk factors associated with reoperation and disease-specific mortality in patients with medullary thyroid carcinoma. JAMA Surg 153: 52-59, 2018.

7. Ceolin L, Duval M, Benini AF, Ferreira CV and Maia AL: Medullary thyroid carcinoma beyond surgery: Advances, challenges, and perspectives. Endocr Relat Cancer 26: R499-R518, 2019.

8. Meijer JA, le Cessie S, van den Hout WB, Kievit J, Schoones JW, Romijn JA and Smit JWA: Calcitonin and carcinoembryonic antigen doubling times as prognostic factors in medullary thyroid carcinoma: A structured meta-analysis. Clin Endocrinol (Oxf) 72: 534-542, 2010.

9. Zhang Y, Zhong Q, Chen X, Fang J and Huang Z: Diagnostic value of microRNAs in discriminating malignant thyroid nodules from benign ones on fine-needle aspiration samples. Tumour Biol 35: 9343-9353, 2014.

10. Nishino M: Molecular cytopathology for thyroid nodules: A review of methodology and test performance. Cancer Cytopathol 124: 14-27, 2016.

11. Mohr AM and Mott JL: Overview of microRNA biology. Semin Liver Dis 35: 3-11, 2015.

12. Liu X, Jiao Z, Chen H and Wang L: A correlational study on miR-34s and cervical lesions. Eur J Gynaecol Oncol 39: 786-789, 2018.

13. Lu TX and Rothenberg ME: MicroRNA. J Allergy Clin Immunol 141: 1202-1207, 2018.

14. Tian T, Wang J and Zhou X: A review: microRNA detection methods. Org Biomol Chem. 13: 2226-2238, 2015.

15. Catalanotto C, Cogoni C and Zardo G: microRNA in control of gene expression: An overview of nuclear functions. Int J Mol Sci 17: 1712, 2016.

16. Yeh M, Oh CS, Yoo JY, Kaur B and Lee TJ: Pivotal role of microRNA-138 in human cancers. Am J Cancer Res 9: 1118-1126, 2019.

17. Humphries $B$, Wang $Z$ and Yang $C$ : microRNA regulation of epigenetic modifiers in breast cancer. Cancers (Basel) 11: 897, 2019.

18. Chu YH, Hardin H, Schneider DF, Chen H and Lloyd RV: microRNA-21 and long non-coding RNA MALAT1 are overexpressed markers in medullary thyroid carcinoma. Exp Mol Pathol 103: 229-236, 2017.

19. Hou W, Zhang H, Bai X, Liu X, Yu Y, Song L and Du Y: Suppressive role of miR-592 in breast cancer by repressing TGF-ß2. Oncol Rep. 38: 3447-3454, 2017.

20. Slattery ML, Mullany LE, Sakoda LC, Wolff RK, Samowitz WS and Herrick JS: Dysregulated genes and miRNAs in the apoptosis pathway in colorectal cancer patients. Apoptosis 23: 237-250, 2018.

21. Xu Y, Li K, Wang SB and Yang SG: Mir-592 functions as a tumor suppressor in acute myeloid leukemia by targeting ROCK1 and predicts patients' prognosis. Eur Rev Med Pharmacol Sci 23: 1610-1619, 2019.

22. Gao S, Chen J, Wang Y, Zhong Y, Dai Q, Wang Q and Tu J: MiR-592 suppresses the development of glioma by regulating rho-associated protein kinase. Neuroreport 29: 1391-1399, 2018.

23. Clough $\mathrm{E}$ and Barrett T: The gene expression omnibus database. Methods Mol Biol 1418: 93-110, 2016. 
24. Ashburner M, Ball CA, Blake JA, Botstein D, Butler $\mathrm{H}$, Cherry JM, Davis AP, Dolinski K, Dwight SS, Eppig JT, et al: Gene ontology: Tool for the unification of biology. The gene ontology consortium. Nat Genet 25: 25-29, 2000.

25. The Gene Ontology Consortium: The gene ontology resource: 20 years and still going strong. Nucleic Acids Res 47: D330-D338, 2019.

26. Nikiforova M N , Tseng G C , Steward D , et al. MicroRNA Expression Profiling of Thyroid Tumors: Biological Significance and Diagnostic Utility. Journal of Clinical Endocrinology \& Metabolism, 93:1600-1608, 2008.

27. Kanehisa M, Sato Y, Furumichi M, Morishima K and Tanabe M: New approach for understanding genome variations in KEGG. Nucleic Acids Res 47: D590-D595, 2019.

28. Kanehisa M: Toward understanding the origin and evolution of cellular organisms. Protein Sci 28: 1947-1951, 2019.

29. Besso MJ, Rosso M, Lapyckyj L, Moiola CP, Matos ML, Mercogliano MF, Schillaci R, Reventos J, Colas E, Gil-Moreno A, et al: FXYD5/dysadherin, a biomarker of endometrial cancer myometrial invasion and aggressiveness: Its relationship with TGF- $\beta 1$ and NF- $\kappa B$ pathways. Front Oncol 9: 1306, 2019.

30. Cari L, Nocentini G, Migliorati G and Riccardi C: Potential effect of tumor-specific treg-targeted antibodies in the treatment of human cancers: A bioinformatics analysis. Oncoimmunology 7 : e1387705, 2018

31. Li C, Zhou D, Jiang X, Liu M, Tang H and Mei Z: Identifying hepatocellular carcinoma-related hub genes by bioinformatics analysis and CYP2C8 is a potential prognostic biomarker. Gene 698: 9-18, 2019.

32. Zhu G, Xie L and Miller D: Expression of microRNAs in thyroid carcinoma. Methods Mol Biol 1617: 261-280, 2017.

33. Orlandella FM, Mariniello RM, Iervolino PLC, Imperlini E, Mandola A, Verde A, De Stefano AE, Pane K, Franzese M, Esposito S, et al: miR-650 promotes motility of anaplastic thyroid cancer cells by targeting PPP2CA. Endocrine 65: 582-594, 2019

34. Zhao $\mathrm{P}$, Ma W, Hu Z, Zhang $\mathrm{Y}$, Zhang $\mathrm{S}$ and Wang $\mathrm{Y}$ Up-regulation of miR-340-5p promotes progression of thyroid cancer by inhibiting BMP4. J Endocrinol Invest 41: 1165-1172, 2018.

35. Liu X, Fu Y, Zhang G, Zhang D, Liang N, Li F, Li C, Sui C, Jiang J, Lu H, et al: Mir-424-5p promotes anoikis resistance and lung metastasis by inactivating hippo signaling in thyroid cancer. Mol Ther Oncolytics 15: 248-260, 2019.

36. Zhang W, Ji W and Zhao X: Mir- 155 promotes anaplastic thyroid cancer progression by directly targeting socs1. BMC Cancer 19 : 1093, 2019.

37. Gong Y, Wu W, Zou X, Liu F, Wei T and Zhu J: Mir-26a inhibits thyroid cancer cell proliferation by targeting arpp19. Am J Cancer Res 8: 1030-1039, 2018.

38. Han J, Zhang M, Nie C, Jia J, Wang F, Yu J, Bi W, Liu B, Sheng R, $\mathrm{He}$ G, et al: Mir-215 suppresses papillary thyroid cancer proliferation, migration, and invasion through the AKT/GSK-3//Snail signaling by targeting ARFGEF1. Cell Death Dis 10: 195, 2019.

39. Liu H, Deng H, Zhao Y, Li C and Liang Y: Lncrna xist/miR-34a axis modulates the cell proliferation and tumor growth of thyroid cancer through met-Pi3K-Akt signaling. J Exp Clin Cancer Res 37: 279, 2018

40. Wang P, Gu J, Wang K, Shang J and Wang W: miR-206 inhibits thyroid cancer proliferation and invasion by targeting RAP1B. J Cell Biochem 120: 18927-18936, 2019.

41. Saiselet M, Pita JM, Augenlicht A, Dom G, Tarabichi M, Fimereli D, Dumont JE, Detours V and Maenhaut C: miRNA expression and function in thyroid carcinomas: A comparative and critical analysis and a model for other cancers. Oncotarget 7: $52475-52492,2016$.
42. Chu YH and Lloyd RV: Medullary thyroid carcinoma: Recent advances including microRNA expression. Endocr Pathol 27: 312-324, 2016

43. Abraham D, Jackson N, Gundara JS, Zhao JT, Gill AJ, Delbridge L, Robinson BG and Sidhu SB: microRNA profiling of sporadic and hereditary medullary thyroid cancer identifies predictors of nodal metastasis, prognosis, and potential therapeutic targets. Clin Cancer Res 17: 4772-4781, 2011.

44. Hudson J, Duncavage E, Tamburrino A, Salerno P, Xi L, Raffeld M, Moley J and Chernock RD: Overexpression of miR-10a and miR-375 and downregulation of YAP1 in medullary thyroid carcinoma. Exp Mol Pathol 95: 62-67, 2013.

45. Yerukala Sathipati S and Ho SY: Identifying a miRNA signature for predicting the stage of breast cancer. Sci Rep 8: 16138, 2018.

46. Liu M, Zhi Q, Wang W, Zhang Q, Fang T and Ma Q: Up-regulation of miR-592 correlates with tumor progression and poor prognosis in patients with colorectal cancer. Biomed Pharmacother 69: 214-220, 2015.

47. Fu Q, Du Y, Yang C, Zhang D, Zhang N, Liu X, Cho WC and Yang Y: An oncogenic role of miR-592 in tumorigenesis of human colorectal cancer by targeting forkhead box o3a (FoxO3A). Expert Opin Ther Targets 20: 771-782, 2016.

48. Lv Z, Rao P and Li W: MiR-592 represses FOXO3 expression and promotes the proliferation of prostate cancer cells. Int J Clin Exp Med 8: 15246-15257, 2015.

49. He Y, Ge Y, Jiang M, Zhou J, Luo D, Fan H, Shi L, Lin L and Yang L: MiR-592 promotes gastric cancer proliferation, migration, and invasion through the Pi3K/Akt and MAPK/ERK signaling pathways by targeting spry2. Cell Physiol Biochem 47: 1465-1481, 2018.

50. Bragelmann J, Klümper N, Offermann A, von Mässenhausen A, Böhm D, Deng M, Queisser A, Sanders C, Syring I, Merseburger AS, et al: Pan-cancer analysis of the mediator complex transcriptome identifies CDK19 and CDK8 as therapeutic targets in advanced prostate cancer. Clin Cancer Res 23: 1829-1840, 2017

51. McDermott MS, Chumanevich AA, Lim CU, Liang J, Chen M, Altilia S, Oliver D, Rae JM, Shtutman M, Kiaris H, et al: Inhibition of CDK8 mediator kinase suppresses estrogen dependent transcription and the growth of estrogen receptor positive breast cancer. Oncotarget 8: 12558-12575, 2017.

52. Liang J, Chen M, Broude EV and Roninson IB: Role of transcription-regulating kinase CDK8 in colon cancer metastasis. Oncotarget 10: 622-623, 2019.

53. Philip S, Kumarasiri M,Teo T, YuM and Wang S: Cyclin-dependent kinase 8: A new hope in targeted cancer therapy? J Med Chem 61: 5073-5092, 2018

54. Crown J: CDK8: A new breast cancer target. Oncotarget 8: 14269-14270, 2017.

55. Song W, Wu S, Wu Q, Zhou L, Yu L, Zhu B and Gong X: The microRNA-141-3p/CDK8 pathway regulates the chemosensitivity of breast cancer cells to trastuzumab. J Cell Biochem 120: 14095-14106, 2019.

56. Wei R, Kong L, Xiao Y, Yuan H, Song Y, Wang J, Yu H, Mao S and $\mathrm{Xu} \mathrm{W}$ : CDK8 regulates the angiogenesis of pancreatic cancer cells in part via the CDK8- $\beta$-catenin-klf2 signal axis. Exp Cell Res 369: 304-315, 2018.

57. Xing S, Xu Q, Fan X, Wu S and Tian F: Downregulation of miR-138-5p promotes non-small cell lung cancer progression by regulating CDK8. Mol Med Rep 20: 5272-5278, 2019.

This work is licensed under a Creative Commons Attribution-NonCommercial-NoDerivatives 4.0 International (CC BY-NC-ND 4.0) License. 